\title{
MANAGE YOUR SUCCESS OF BUSINESS
}

\author{
Dr. Pravin M. Chandragiriwar \\ Associate Professor(Commerce) \\ Bhawabhuti Mahavidyalaya, Amgaon.Dist. Gondia ( M.S,) \\ R.T.M.University Nagpur.
}

\begin{abstract}
The success of any business starts with how well you are able to manage yourself. Some useful tips for self management. Before you have even started your business, start developing a leadership vision. The responsibility for the growth you wish to achieve in your businesses, squarely lies on your shoulder. The benefit that is likely to accrue by implementing the decision and come out a winner. When you start a business, failure can be an important part of learning and growing. Unnecessary meetings, interruptions and inefficiency may sap you of your energy, leaving a little for the important aspects of business. Create an environment where people have the opportunity to increase their skills and are rewarded for doing so that.

To be succeeding in business today, you have need of to be flexible and have good planning and organizational skills. Many people start a business thinking that they turn on their are computers or open the doors and start making money, One and only to find that making money in a business is much more difficult than they are thinking. You can continue away from this in your business ventures by taking your time and planning out all the necessary stepladder you need to achieve success. Anything type of business you want to start, using the following nine strategy can help you be successful in your project.
\end{abstract}

\section{INDRODUCTION}

THE Government of India's Ease of Doing Business World Bank ranking has jumped to a respectable $77^{\text {th }}$ place, meaning that the facilities accorded by the Government for the Entrepreneurs are getting better and better. Economist world over are predicting an upswing in the business scenario, in the soon-to-become super power India. The Start ups in India are also in the never before space, as they are getting support from the Government, Institutions and several NGO's too.

But in spite of all the good work the Start ups are attempting, there are glitches in their management practices, which they could well do by ironing out their rough edges. Here are some mantras for the Start Ups to sail smoothly and in order to scale up in their business

\section{TIPS FOR INCRESING A SUCCESSFUL BUSINESS:-}

1. Get Organized :-To achieve business success you require to be organized. It will be help you complete household tasks and stay on top of things to be done. On the good way to be organized is to create a to-do list each day. As you are completed each item, verify it off your list. This will be ensuring that you are not forgetting anything and completing all the tasks that are necessary to the survival of your business.

2. Keep thorough Records:-By doing so that, you will know where the business stands financially, what possible challenges you could will be in front of the Just knowing this gives you time to time generate strategies to overcome all challenges.

3. Study Your Competition:-Competition breeds the best outcome. To be successful, you can not be frightened to study and learn from you are competitors. After all, they may be doing something right that you can put into practice in your business to make more money.

4. Understand the Risks:-The key to being successful is taking calculated risks to help your business produce. If you can answer this question are problems, then you know what the worst-case situation is. This knowledge will allow you to take the kinds of calculated risks that can generate wonderful rewards. 
5. Be Creative:-Always be looking for ways to improve your business and make it position out from the competition. Recognize that you do not know everything and be open to new thoughts and different approaches to your business.

6. Stay Focused:-The old saying "Rome was not built in a day" applies here. Just since you open a business does not mean you are going to immediately start making money. It takes time to let people know who you are, so that stay focused on achieving your short-term goals.

7. Prepare to Make Sacrifices:-But after you open your doors, your work has just begun. In many cases you have to put in more time to time than you would if you were working for someone as well, which may mean spending less time with family and friends to be successful that.

8. Provide Great Service:-There are many successful businesses that forget that providing great customer service is important now. If you provide better service for your customers, they will be more inclined to come to you the next time they need something as a substitute of going to your competition.

9. Be Consistent:-Constancy is a key component to making money in business. They have to keep doing what is necessary to be successful day in and day out that. This will create longterm positive habits that will help you make money in the long run for.

\section{MANAGING YOURSELF:}

The success of any business starts with how well you are able to manage yourself. Some useful tips for self management are as follows:

\section{CREATE A LEADERSHIP VISION:}

Before you have even started your business, start developing a leadership vision. It should be that a compelling image of an achievable opportunity. Describe the kind of leader you want to become and visualize how your leadership acumen is going to make a difference to your business.

\section{TURN YOUR WEAKNESSES INTO STRENGTH:}

With appropriate comment you will come to know which are areas of your personality, you need to work on. Like a pro tennis player, make sure to work on your backhand.

\section{TAKE RESPONSIBILITY FOR YOUR GROWTH:}

Remember that the responsibility for the growth you wish to achieve in your businesses, squarely lies on your shoulder. This requires a periodic evaluate of your actions and its importance. Be honest about your strengths and weaknesses.

\section{MAKE MASTERFUL DECISIONS:}

The construction of any business depends on how best possible the decision making process has been. Whether you make decisions swiftly, decisively or cautiously make sure that you optimize your inputs by getting the insights of a few trusted people and finally analyze the cost viz a viz the benefit that is likely to accrue by implementing the decision and come out a winner.

\section{ADOPT A GROWTH MINDSET:}

Many Start Up owners are so paranoid of failing that they spend a lot of time and energy in finding ways and means of not failing. When you start a business, failure can be an important part of learning and growing. You must adapt a growth mind set and accept failure a part of the process of skill development. Don't try to do only the doable things.

\section{MANAGE YOUR TIME \& ENERGY:}

Entrepreneurship can truly be a draining profession. Unnecessary meetings, interruptions and inefficiency may sap you of your energy, leaving a little for the important aspects of business. For optimum utilization of your time and energy make sure to have a to do list, attend to the important things first and then schedule time for the not-so urgent things. 


\section{BE OPEN TO CONSTRUCTIVE CRITICISM:}

Constructive criticism is are important for creativity, innovation and problem solving. A good leader will always welcome criticism from all quarters gracefully and try to work on them.

\section{MANAGING YOUR TEAM \\ Lead Confidently:}

Many Start Up owners start pretty young so they are full of doubts, whether their team will believe in their ability to get things done? In such case the best thing to do would be to show your supreme confider ice in yourself, your product and your company. You must make things happen by engaging your talent.

\section{Support Your Team to Bring Out The Best In Them:}

Countless distractions, threats and roadblocks may be the order of the day for your team. Make sure that as a good boss you shield them these annoyances. Involve your team in the project by asking them to share their ideas.

\section{Let Your Employees Fall Occasionally:}

A good leader must let the employees make mistake occasionally so that they are not afraid of failure and also can get it right the next time.

\section{Resolve Conflict Like A Pro:}

No organization can function without manpower and where manpower, the most volatile of all resources is present - conflicts are bound to arise. Difference in education, culture, upbringing, religion can all be reasons for conflict among the team. As a good leader you must try to nip conflict in the bud and keep the team's emotion in check. Ensure that the conflict resolution is done to the satisfaction of all concerned.

\section{Communicate, Communicate and Communicate:}

Communication is the lifeline of any organization. It is observed that if the channels of communication are open and is in two way - productivity increases. The more the clarity the employee has about your vision, mission and the dream for your company, the better they will perform.

\section{Motivate Your Employees:}

A pat on the back for a job well done always works well for any employee. Never be stingy in your praise as there is no such thing as employees getting spoilt when you heap praise on them. On the contrary it is likely to create a sense on belongingness and loyalty among employees.

\section{Empower Your Employees :}

A true leader encourages his team to share information, take decision and tale risk. Create an the environment where people have the opportunity to expand their skills and are rewarded for doing so that.

\section{MANAGING YOUR BUSINESS}

KEEP IT SIMPLE : you may be into the most complex of business, but unless you keep the process simple, you are more likely to fail as people working with you may not understand all the intricacy involved, resulting in a mess. As a leader you must align your goals with the people working for you.

BE READY FOR THE CHANGE: In the fast paced global economy of today, be prepared to embrace the change taking place every moment, lest you become the also ran. Markets change, customers change and even your company changes - be prepared so that you don't miss out on important opportunities. 
BE PREPARED FOR THE CRISIS : A good leader anticipates crisis much before it actually occurs. You cannot always avoid disasters. Companies are known to come across unforeseen and unpredictable situations. You must sharpen your sixth sense to sniff out such situations so that you can arm yourself sufficiently to tide over such situations.

PRACTICE COST CUTTING : Many companies fail not because they are not able to generate profit but because they are not able to control the spiraling cost. You must from day one make it a practice to stretch your rupee to the maximum. The best way to cut cost is to lay down a strategy and man oeuvre around it. Of course, cutting cost does not in any way mean being stingy or a miser.

WIN YOUR CUSTOMER'S HEART : You may be dealing in Robots or Baby Soaps, the best way to develop a sustainable business in is simply by winning your customer's heart. Customers are the ones who can make or break your business. Train your people to go out of their way when attending your customers. In the day and age of technology, where opinion travel really fast, a satisfied customer can be the brand ambassador for your business.

BOOST YOUR COMPANY'S IMAGE THROUGH SOCIAL MEDIA : Your company's presence in social media cannot be over emphasized, in this day and age of digitalization. You must choose your medium wisely so get the maximum leverage. In case you are not tech savvy, do not shy away from seeking professional help to boost your company's on line image.

A PEEP INTO FUTURE: A long term goal is as important for a company as its short term goal. You must be able to visualize where your company will be a decade hence.

\section{CONCLUSION :-}

1. You can also take a 360 degree assessment of your leadership skills by taking regular feedbacks.

2. You can spend more time networking, attending seminars and conferences which wIll not only hone your business skills but may also open up new business opportunities.

3. Instead try things that you are not sure of accomplishing by raising the bar really high.

4. Create a open environment where your people can confidently interact with you so that you can challenge them to get better.

5. communication has to be accompanied by enthusiasm from your side, otherwise it may fall flat on its face.

6. This will help you to integrate all your actions and decision making process in conformity to the long term goals of the company.

7. To achieve business success you require to be organized. It will be help you complete household tasks and stay on top of things to be done.

8. Always be looking for ways to improve your business and make it position out from the competition.

9. This knowledge will allow you to take the kinds of calculated risks that can generate wonderful rewards.

10. There are many successful businesses that forget that providing great customer service is important now.

\section{References :-}

1] Newspaper The Hitavada, Future, Dated 11 December 2018.

2] www.briantracy.com/.../business-success/7-tips-for-growing-a-successful-business...

3] www.briantracy.com/blog/business-success/the-ten-keys-to-business-success/

4] www.ryrob.com/start-business-advice

5] www.investopedia.com > Small Business > Entrepreneurship.

6] https://www.investopedia.com/articles/pf/08/make-money-in-business.asp. 